Submitted on November 22, 2019.

\title{
Fungicidal activity of new 5-arylazo-7-nitro-8-hydroxyquinolines
}

\author{
C Ilya I. Ustinov, ${ }^{1+}$ Anastasia V. Glazunova, ${ }^{2}$ Georgy V. Pescov, ${ }^{2}$ Irina V. Shakhkeldyan, ${ }^{1}$ \\ Yury M. Atroshchenko, ${ }^{1}$ * and Konstantin I. Kobrakov ${ }^{2}$ \\ ${ }^{1}$ Department of Chemistry. ${ }^{2}$ Department of Botany and Technology of Plant Growing. \\ Tula State Lev Tolstoy Pedagogical University. Lenina St., 125. Tula, 300026. Russia. \\ Phone: +7 (4872) 35-78-08. E-mail: bai2688@yandex.ru \\ ${ }^{3}$ Department of Organic Chemistry. State University of Russia. A.N. Kosygin (Technology. Design. Art). \\ Sadovnicheskaya St., 33. Moscow, 117997. Russia. Phone: +7 (495)955-35-58.E-mail: kobrakovk@mail.ru
}

*Supervising author; ${ }^{+}$Corresponding author

Keywords: 5,7-dinitro-8-hydroxyquinoline, azoquinolines, fungicidal activity.

\section{Abstract}

Currently, agricultural production is impossible without the use of chemical plant protection products, so the search for new effective fungicides is an important and urgent task.

A significant part of the systemic fungicides and antimycotics used today are azole derivatives.

Research conducted at the Department of Chemistry is devoted to the analysis of the fungicidal and biological activity of substances of various classes of organic compounds, including derivatives of azoles. Previously published data on the fungicidal activity of 2-methyl-5-nitrobenzoxazole and its derivatives showed that 2-methyl-5-nitrobenzoxazole shows the highest fungicidal activity for all types of fungal cultures used in the study. The second nitro group introduced into the 2-methyl-5-nitrobenzoxazole molecule reduces fungitoxicity by 1.5-2 times. Replacing the methyl group with phenyl significantly reduces the fungicidal activity.

In continuation of these studies, tests of 5-(4'-chlorophenylazo)-7-nitro-8-hydroxyquinoline, 5-(3',5'dimethoxyphenylazo)-7-nitro-8-hydroxyquinoline and 5-(3'-methyl-4'-nitrophenylazo)-7-nitro-8-hydroxyquinoline with respect to $V$. inaequalis, the causative agent of apple scab, $R$. solani, the causative agent of rhizoctonia, $F$. oxysporum, $F$. moniliforme, causative agents of cereal crops, B. sorokiniana - causative agent of root rot and $S$. sclerotiorum - causative agent of white rot.

The radial growth of mycelium was determined according to the method developed by NIITEKHIM, according to which the fungal cultures were sown in nutrient media with the addition of the studied substances. In parallel, a control experiment was conducted in the aquatic environment. The growth of mycelia was controlled by measurements on days 3,6 and 9. The percentage of inhibition of fungal growth was calculated using the Abbott formula.

Analysis of the experimental data demonstrates a higher fungicidal activity of 5-(3',5'-dimethoxyphenylazo)-7-nitro-8-hydroxyquinoline compared with other azoquinolines for all types of fungal cultures used in the study.

\section{References}

[1] V.S. Talismanov, S.V. Popkov. Synthesis and fungicidal activity of 4- (azol-1-ylmethyl) -2-alkyl-2-aryl1,3-dioxolanes. Agrochemistry. 2007. No.5. P.53-57. (russian)

[2] S.L. Kelly, D.C. Lamb, M. Cannieux. An old activity in cytochrome P450 superfamily (CYP51) and a new story of drugs and resistance. Biochem. Soc. Trans. 2001. Vol.29. P.122-128.

[3] H.V. Bossche. Biochemical targets for antifungal azole derivatives. Current topics in medicinal mycology. Ed. McGinnis M.R. Berlin: Shpringer Verlag. 1985. P.313-351.

[4] B.A. Haskin. The mechanism of action of systemic fungicides. ZhVHO. 1988. No.6. P.698-708. (russian)

[5] L.G. Mukhtorov, G.V. Pestsov, M.B. Nikishina, E.V. Ivanova, Yu.M. Atroshchenko, and K.I. Kobrakov. Comparative analysis of fungicidal activity 2-methyl-5-nitrobenzoxazole and its derivatives. Butlerov Communications. 2018. Vol.54. No.4. P.149-155. ROI: jbc-02/18-54-4-149

[6] L.G. Mukhtorov, G.V. Pestsov, M.B. Nikishina, E.V. Ivanova, I.V. Shahkeldyan, Yu.M. Atroshchenko, and K.I. Kobrakov. Effect of nitro groups on the fungicidal activity of benzoxazole. Butlerov Communications. 2018. Vol.54. No.4. P.156-161. DOI: 10.37952/ROI-jbc-01/18-54-4-156

[7] I.I. Ustinov, N.V. Khlytin, I.V. Blokhin, A.N. Shumsky, I.V. Shakhkel'dyan, Yu.M. Atroshchenko, K.I. Kobrakov. Interaction of hydride $\Sigma$-complex of 5,7-dinitro-8-hydroxyquinoline with salts of aromatic 
FUNGICIDAL ACTIVITY OF NEW 5-ARYLAZO-7-NITRO-8-HYDROXYQUINOLINES

156-159

diazo compounds. Izv. Vyssh. Uchebn. Zaved. Khim. Khim. Tekhnol. 2019. Vol.62. No.11. P.85-91.

(russian)

[8] Guidelines for determining the fungicidal activity of new compounds. Cherkasy: NIITEKHIM. 1984. 32p. (russian)

[9] M.N. Golyshin. Fungicides in agriculture. Moscow: Kolos. 1970. 167p. (russian) 